\title{
La necesidad de reconocer los derechos laborales del Teletrabajo
}

\author{
The need to recognize teleworking labor rights
}

Guadalupe Jannet Bonilla García ${ }^{a}$

\begin{abstract}
:
The Covid-19 pandemic marked a before and after regarding labor trends in the world. As for Mexico, the number of workers under the teleworking system increased, therefore, the labor legislation was reformed to recognize this special type of work. For this reason, this document makes a brief journey through the most relevant antecedents of labor law, until reaching the achievement and recognition of the rights and obligations within Telework. For which, making an analysis of these in order to determine the importance of inclusion of Chapter XII Bis in the Federal Labor Law to give legal certainty to all employees who work under the Telecommuting modality.
\end{abstract}

Keywords:

Work at home, technology, telecommunications.

\section{Resumen:}

La pandemia de Covid-19 marcó un antes y un después respecto a las tendencias laborales en el mundo. En cuanto a México, el número de trabajadores bajo el sistema de teletrabajo aumentó, por lo que la legislación laboral se reformó para reconocer esa modalidad de trabajo especial. Por tal motivo, en el presente documento se hace un breve recorrido por los antecedentes más relevantes del Derecho laboral hasta llegar a la conquista y reconocimiento de los derechos y obligaciones dentro del Teletrabajo. Para lo que se hace un análisis de estos, con la finalidad de determinar la importancia de la inclusión del Capítulo XII Bis en la Ley Federal del Trabajo, para darle certeza jurídica a todos los empleados que laboran bajo la modalidad del Teletrabajo.

\section{Palabras Clave:}

Trabajo a domicilio, Tecnología, Telecomunicaciones.

\section{Introducción}

El Derecho laboral es sin duda alguna una disciplina que se encuentra en constante actualización, ya que para cumplir con su objetivo de garantizar los derechos de los sujetos que lo conforman, debe ir ajustándose a las necesidades que la sociedad va presentando. En ese orden de ideas, resulta pertinente abordar un análisis sobre los derechos que se tienen respecto a la figura del Teletrabajo, ya que en fechas recientes cobró gran relevancia no solo en México, sino en la mayor parte de los países latinoamericanos. Estos países, a diferencia de otras naciones pertenecientes a la Unión Europea, no estaban tan familiarizados con esta forma de organización laboral, pero tuvieron que saltar a esta modalidad por motivos de la pandemia que inició a finales del 2019, la cual tuvo su mayor impacto durante 2020, y que actualmente sigue causando estragos en varios sectores, tales como el económico y de salud alrededor del mundo.

Como se mencionó en el párrafo anterior, México no contaba con una legislación que reconociera la figura del teletrabajo, situación que cambió a inicios del presente año dando pie a numerosas interrogantes respecto a su aplicación, por tal motivo, a continuación se abordarán los aspectos más relevantes de esta modalidad con el objetivo de analizar los alcances de los derechos y obligaciones que se adquieren tanto por parte del patrón como del trabajador que es contratado bajo esta forma de organización laboral.

Así mismo, se relatarán brevemente los antecedentes más significativos del derecho laboral para entender la influencia de los fenómenos sociales en el contenido de las leyes en materia de trabajo y su evolución hasta nuestros días. Además, se analizará cómo la pandemia de Covid-19 afectó las relaciones laborales, provocando

\footnotetext{
a Autor de Correspondencia, Universidad Autónoma de Tlaxcala, México. ORCID: https://orcid.org/0000-0001-7720-9345
}

E-mail: jannetbonillagar@hotmail.com 
la migración de miles de trabajadores a la modalidad de teletrabajo.

Finalmente, se establecerán los beneficios que la incorporación del Capítulo XII Bis en la Ley Federal del Trabajo produjo hacia los sujetos implicados en la relación laboral bajo la modalidad del Teletrabajo al incluir y determinar sus derechos y obligaciones.

\section{Contexto histórico de los derechos laborales}

El ser humano y el trabajo han estado ligados desde siempre, puesto que cualquier actividad del hombre encaminada a su supervivencia o la búsqueda de la satisfacción de alguna necesidad llevan revestido un esfuerzo que posteriormente y acompañado de ciertas características sería denominado como trabajo. Sin embargo, debieron pasar varios siglos y diferentes acontecimientos que impactaron a la sociedad de tal manera que dieron como resultado el reconocimiento de los derechos laborales que se tienen hoy en día.

Para empezar, es relevante mencionar que en la edad antigua esta actividad fue prácticamente ignorada por el mundo conocido en ese entonces, ya que como es sabido, los filósofos y juristas en Grecia y en Roma pertenecían a la aristocracia, por lo que poco les importaba garantizar los derechos a favor de sus esclavos, sin embargo, en esta última aparecieron dos instituciones contractuales que marcarían un antecedente para la regulación de los derechos laborales.

Por un lado, el locatio conductio operis o arrendamiento de obra, que se encargaba de regular precisamente la realización de una obra determinada y por otro lado, se encontraba el locatio conductio operarum 0 arrendamiento de servicios, que regulaba la prestación de un determinado servicio, dando como resultado el reconocimiento de dos elementos característicos de una relación laboral: la prestación de un servicio personal y la remuneración (Dávalos, 2008). Sin embargo, la fuerza de trabajo no era reconocida meramente como se conoce hoy en día, ya que los esclavos no eran vistos como personas sino como objetos propiedad de sus amos.

Ahora bien, con la caída el Imperio Romano de Occidente en el 476 d.C. surge la Edad Media, la cual se caracteriza por ser una época de violencia ya que el control que ejercía el Occidente sobre las regiones del viejo continente se había perdido. Lo anterior provocó el surgimiento de los gremios, los cuales tenían la finalidad de agrupar a las personas de acuerdo a su ocupación u oficio para protegerse entre sí y regular su actividad mediante estatutos (Machicado, 2010).

Estos gremios también marcarían un antecedente de la legislación laboral actual, ya que dentro de estas corporaciones los sujetos se clasificaban en maestros, oficiales y compañeros; siendo los primeros los dueños de los medios de producción que posteriormente se conocerían como patrones y a los segundos y terceros como trabajadores.

Durante estas dos primeras etapas se encuentra un Derecho laboral bastante escaso, ya que como se dijo anteriormente, la figura del trabajador no era reconocido como tal y por lo tanto, sus derechos tampoco eran algo que le preocupara a la sociedad que regía en aquel entonces; ya que pertenecían a la clase social alta.

Fue precisamente en esta época que se presentó el auge del feudalismo, por lo que no fue sino hasta la época moderna, con la caída del Imperio de Oriente en 1453 d.C. en que el verdadero derecho laboral comenzó a tomar forma; pues es durante esta época donde surge lo que Voltaire denominó Renacimiento, periodo que comprendió del 1450 al 1600 y en el cual surgieron las grandes corrientes filosóficas que marcaron un parte aguas no sólo en el mundo del derecho sino en la sociedad en general.

El mencionado periodo del Renacimiento se fundamenta en la teoría del derecho natural y del ser humano que posteriormente tomarían la forma de una declaración Universal de los Derechos del hombre y del ciudadano, en 1789, dando pie a la regulación de los derechos de los trabajadores para asegurar su dignidad como seres humanos (Margadant, 2007).

En lo que respecta a la época contemporánea, hubo gran influencia por parte de Carlos Marx y Federico Engels, los cuales fueron reconocidos pensadores socialistas quienes a través de sus obras lucharon a favor de un Estado más justo y con sentido humano.

Ellos denunciaron la explotación de los trabajadores y las malas condiciones de trabajo a las que eran expuestos por parte de sus empleadores, generando en la sociedad un gran descontento ante tales desigualdades e injusticias y provocaron un despertar hacia la búsqueda de los derechos sociales (Dávalos, 2008).

En cuanto a México, después de una serie de luchas por la conquista de los derechos civiles y políticos a través de una revolución, finalmente el 5 de febrero de 1917 se promulga la Constitución Política en la que a través de su artículo 123 se reconocen las garantías mínimas a favor de los trabajadores cosa que en ese momento justificó Alfonso Cravioto' al afirmar:

Así como Francia, después de su revolución, ha tenido el alto honor de consagrar en la primera de sus cartas magnas los inmortales derechos del hombre, así la revolución mexicana tendrá el orgullo legítimo de mostrar al mundo que es la primera en consignar en una Constitución los sagrados derechos de los obreros (Dávalos 2008:60) 
Esas palabras representaron el ánimo que embargaba a todo el Congreso Constituyente por buscar reconocer a aquel sector de la población; el cual había sido ignorado por los gobiernos, pero que a partir de ese momento marcaría el despertar nacional hacia la conquista de más derechos a favor de los obreros.

Ese despertar se vería reflejado mediante diversos trabajos legislativos, realizados por los Estados y que en 1931 se traducirían en una única ley en materia laboral, cuya aplicación correspondería a las autoridades federales y locales mediante una distribución de competencia. Esa sería la primera Ley Federal del Trabajo, a la que seguiría la de 1970, la cual, a pesar de sus diversas reformas, sigue en vigor hasta el día de hoy.

Como se ha observado en los acontecimientos descritos anteriormente, el contenido del Derecho laboral se va enriqueciendo conforme la sociedad va evolucionando $y$, lo único que hace es responder a las necesidades que se presentan a través de los diferentes fenómenos sociales, tales como guerras, conflictos sociales, avances tecnológicos y pandemias, entre otros.

\section{¿Dónde queda el teletrabajo?}

Ahora bien, como se ha descrito, los derechos laborales como se tienen hoy en día no se lograron de la noche a la mañana, sino que ha sido un largo camino al que seguramente le resta mucho tramo por recorrer.

El Derecho es una disciplina en constante evolución y más aun tratándose del derecho laboral, así lo menciona Dávalos (2008), al decir que es un derecho en constante expansión que busca incorporar actividades que no estaban reguladas por la ley laboral o que van surgiendo con las necesidades de la sociedad.

En ese sentido y debido a los avances tecnológicos, una de esas actividades reglamentadas recientemente ha sido el Teletrabajo, el cual se presenta con el desarrollo de las tecnologías de información. Sin embargo, sus inicios se identifican desde años atrás, mediante la figura del trabajo a domicilio, el cual se presenta mucho antes del capitalismo mediante la figura de los artesanos que solían tener sus talleres en casa y abastecían con su trabajo manual a la industria naciente.

Aunque, posteriormente, con el crecimiento económico, se generó la necesidad de producir a gran escala, provocando que muchos de los artesanos se concentraran en un solo lugar para optimizar la producción. Hubo quienes continuaron son su trabajo fuera de las fábricas, por lo que el trabajo manual a pequeña escala no desapareció, incluso llegó a considerarse como una extensión de la empresa.

Por mucho tiempo, esta forma de trabajo fue poco valorada. Sin embargo, con el paso de los años ha ido tomando más fuerza; sobre todo en este época en que la sociedad ha tenido que echar mano de esta modalidad para mantener a flote la economía mundial.

En cuanto a su definición, uno de los más sobresalientes es otorgado por la Organización Internacional del Trabajo (OIT), al definirlo como:

El trabajo que una persona, designada como trabajador a domicilio realiza: (i) en su domicilio o en otros locales que escoja, distinto de los locales de trabajo del empleador; (ii) a cambio de una remuneración, (iii) con el fin de elaborar un producto o prestar un servicio conforme a las especificaciones del empleador, independientemente de quien proporcione el equipo, los materiales $u$ otros elementos utilizados para ello". (OIT, 1996: s/p).

La definición anterior no se refiere meramente al teletrabajo, sin embargo, es utilizada como fuente normativa de tal concepto, ya que encierra características básicas del teletrabajo como lo es la realización de una actividad en un lugar distinto a la empresa a cambio de una remuneración y, aunque falta el elemento de las telecomunicaciones se pude observar el indicio de dicho concepto.

En cuanto a la ratificación del acuerdo 177, solamente once naciones lo han hecho, destacando a Argentina y Eslovenia, el primero al ser el único país perteneciente a América Latina y el Caribe que lo ha llevado a cabo y el segundo por ser el último que lo hizo".

Por otro lado, México se encuentra entre los países que realizaron las sumisiones aunque no lo ratificaron, lo que de alguna manera deja entrever la precaria situación en la que se encuentra el país y las demás naciones pertenecientes a América Latina, respecto a dicho tema, ya que no existe algún instrumento regional que regule el trabajo a domicilio y por tal motivo, tampoco respecto al teletrabajo.

En contraste con lo anterior, los países europeos reconocieron la necesidad de contar con un acuerdo en materia de Teletrabajo que regule y estandarice las condiciones laborales a las que tanto patrones como trabajadores que se encuentren bajo esta modalidad deberán someterse, por lo que el 16 de julio de 2002 firmaron el Acuerdo Marco Europeo sobre Teletrabajo en el que establecen:

El Teletrabajo es una forma de organización y/o de realización del trabajo, utilizando las tecnologías de la información en el marco de un contrato o de una relación de trabajo, en la cual un trabajo que podría ser realizado igualmente en los locales de la empresa se efectúa fuera de estos locales de forma regular (AMET, 2002: 2).

Así mismo, en el texto del documento se establece el carácter voluntario del teletrabajo, las condiciones del 
empleo que deberán ser iguales a las de un trabajador que labora en las instalaciones de la empresa; la obligación del patrón de facilitar, instalar y mantener el equipo necesario para el teletrabajo, así como especificar las limitaciones a las que deberá someterse el trabajador respecto a la utilización del equipo y las herramientas digitales que le hayan sido proporcionados.

Por otro lado, esta figura legal también fue reconocida por la Organización Internacional del Trabajo (OIT) en su tesauroiii, el cual lo define como "Trabajo a distancia (incluido el trabajo a domicilio) efectuado con auxilio de medios de telecomunicación y/o de una computadora" (OIT, 2021: s/p).

En cuanto a México, esta figura de trabajo especial se incorporó a la legislación mexicana mediante decreto publicado en el Diario Oficial de la Federación de fecha 11 de enero de 2021 en el que se reforma el artículo 311 de la Ley Federal del Trabajo, que regula el trabajo a domicilio y en el que se adiciona el capítulo XII Bis, en materia de teletrabajo (DOF, 2021).

\section{La moda del Teletrabajo en tiempo de pandemia}

En noviembre de 2019 se escuchaba la noticia de que en Wuhan China se presentaba un peligro sanitario por un nuevo virus, acontecimiento que se consideraba algo ajeno al resto del mundo. No obstante, el 30 de enero de 2020, la Organización Mundial de la Salud declaró la epidemia de Covid-19 una emergencia de salud pública y posteriormente, el 11 de marzo de ese mismo año, al presentarse 118.000 casos en 114 países, y 4291 muertes fue caracterizada como Pandemia (Organización Panamericana de la Salud, 2020).

Ante tal situación, en todo el mundo, gobiernos, organismos, empresas y la sociedad en general comenzaron a implementar los mecanismos necesarios para enfrentar la crisis y frenar los contagios del virus, obligando el cierre de las empresas con actividad no esencial. Lo que de acuerdo con los datos de la Organización Internacional del Trabajo, se estima una pérdida de $10.3 \%$ de las horas de trabajo en el segundo trimestre de 2020 , equivalente a 25 millones de empleos (Weller, 2020).

En ese sentido, las empresas tuvieron que migrar a la modalidad de trabajo a distancia o teletrabajo para disminuir, en la medida de lo posible, las pérdidas económicas que se proyectaban para ese año.

De esta situación, México se encontró ante un reto mayor, a diferencia de los países con un mayor desarrollo económico, ya que de acuerdo con estudios realizados en este campo, se determinó que los factores económicos y ocupacionales, así como el acceso a internet y la posibilidad de poseer equipos de cómputo son elementos importantes para realizar trabajo a domicilio, específicamente mediante la modalidad de Teletrabajo.

En esos mismos estudios se afirma que la posibilidad de trabajar bajo este sistema aumenta en gran medida con el nivel de desarrollo económico del país (OIT, 2020).

En ese momento, México no contaba con la normatividad que regulara el teletrabajo, ya que la Ley Federal del Trabajo únicamente tenía contemplado el trabajo a domicilio. Aunque en esencia comparten varios rasgos similares, era necesario el reconocimiento de esa modalidad, ya que millones de trabajadores se encontraban a la deriva dentro de un nuevo sistema que hasta ese momento había sido poco explorado en el país, corriendo el riesgo de vulnerar sus derechos por parte de los patrones.

Ante tal circunstancia, hubo gran interés por parte de legisladores, organizaciones, gobierno, empresarios y en general, toda la sociedad sobre el tema del Teletrabajo, lo que ocasionó un aumento significativo de conferencias, talleres, convenciones y artículos que trataban sobre el tema, en cuanto a sus alcances y desafíos, esa circunstancia lo refleja perfectamente la declaración de la Organización Internacional del Trabajo al decir:

Esta nueva era del teletrabajo requerirá un uso mucho más amplio de un nuevo tipo de gestión basado en la confianza y en la obtención de resultados, y una nueva forma de trabajar, más autónoma, más flexible y mejor adaptada a las circunstancias y preferencias individuales de los trabajadores (OIT, 2020: 4).

De acuerdo a los datos del INEGI (2020), en abril de 2020 había alrededor de 32.9 millones de personas activos laboralmente, de las cuales $23.5 \%$ son los que trabajan a distancia como se muestra en la figura 1.

Figura 1. Indicadores de población ocupada de 18 años y más usuaria de teléfono que trabaja desde casa por COVID-19

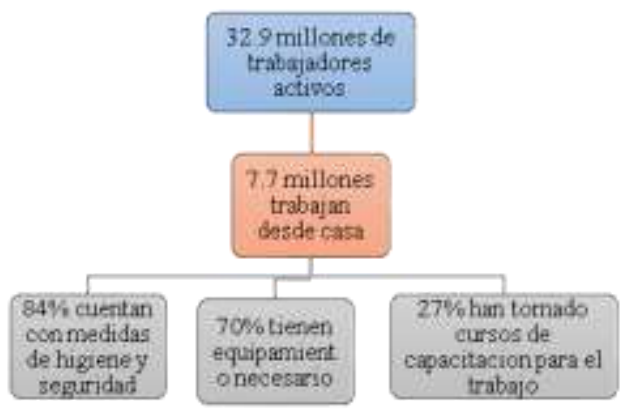

Fuente : INEGI, Encuesta telefónica sobre COVID-19 y mercado laboral (Abril 2020)

Durante la contingencia sanitaria las empresas hicieron un enorme esfuerzo para mantenerse a flote, así mismo, 
los trabajadores tuvieron que enfrentarse ante la incertidumbre del porvenir. De esa misma encuesta, se reporta que el $44.2 \%$ de los trabajadores percibieron su salario de manera parcial mientras que $17.3 \%$ no lo recibió lo que generó una desaceleración económica en el país.

Por otro lado, como lo muestra la Figura 1, solamente el $70 \%$ de las personas contaba con el equipo necesario para realizar su trabajo desde su hogar, de ahí la necesidad de crear un ordenamiento que regule esa situación, ya que de lo contrario, el trabajador quedaría en desamparo para poder cumplir con sus funciones, ya que no existiría la obligación por parte del patrón de garantizar dicho equipamiento.

Así mismo, en relación con el servicio de telecomunicación, muchos de los hogares no contaban con conexión de internet mediante banda ancha, por lo que generó una inversión que no estaba contemplada ni por los patrones ni mucho menos por los trabajadores.

De la misma forma sucedió en materia de higiene y seguridad, ya que de esos 7.7 millones de personas sólo $84 \%$ gozaban de ese derecho, ya que ante la falta de reglamentación, muchos fueron considerados como trabajadores independientes y, de acuerdo a los datos de la OIT (2020), el 90\% de los trabajadores a distancia se encuentran en trabajo informal, por lo que generó una desigualdad respecto a los empleados que laboraban en el establecimiento del patrón.

Actualmente, las empresas en el mundo comienzan poco a poco a reintegrarse a sus actividades, preparando los mecanismos de seguridad para que sus trabajadores regresen a sus oficinas, fábricas o comercios sin que esto represente un riesgo de salud. Sin embargo, esto no se puede hacer de un momento a otro, ya que de no respetarse las medidas correspondientes se podría estar en presencia de una tercera ola de contagio en el país, por lo que el crecimiento de la tendencia en la modalidad del Teletrabajo no fue algo que pertenezca de forma exclusiva al 2020, pues seguramente seguirá siendo más alta de lo que era antes de la pandemia (OIT, 2020).

Por otro lado, las tendencias laborales post pandemia apuntan que muchas de las empresas mantendrán un sistema hibrido o mixto lo que deja ver que la modalidad del teletrabajo llegó para quedarse (OIT, 2020).

\section{Los Derechos en el Teletrabajo}

El teletrabajo, como se mencionó párrafos atrás, es una modalidad recientemente incorporada a la Ley Federal del Trabajo dentro del Título sexto denominado "Trabajos especiales", ya que como su nombre lo indica, consta de ciertas peculiaridades que lo hacen distinto al trabajo común o tradicional, es por ello la pertinencia de analizar el contenido de la legislación respecto a los derechos y obligaciones que se desprenden de ella.

El artículo 330-A de la Ley Federal del Trabajo lo define de la siguiente manera:

EL teletrabajo es una forma de organización laboral subordinada que consiste en el desempeño de actividades remuneradas, en lugares distintos al establecimiento o establecimientos del patrón, por lo que no se requiere la presencia física de la persona trabajadora bajo la modalidad de teletrabajo, en el centro de trabajo, utilizando primordialmente las tecnologías de la información y comunicación, para el contacto y mando entre la persona trabajadora bajo la modalidad de teletrabajo y el patrón (DOF, 2021:325)

De la definición anterior se puede notar que comparte características semejantes a las del trabajo a domicilio, sin embargo, aunque ambas modalidades se refieren a las actividades que un trabajador puede desarrollar en un lugar distinto al de la empresa, el artículo 330-A en su párrafo cuarto establece de manera puntual que para que sean aplicables los lineamientos de la modalidad de teletrabajo, la relación laboral deberá desarrollarse más del cuarenta por ciento del tiempo en el domicilio del trabajador o en cualquier otro elegido por éste, siempre y cuando sea distinto al establecimiento del Patrón.

Así mismo, otra peculiaridad consiste en que el teletrabajo debe contar con el manejo de las tecnologías de información y comunicación, las cuales son definidas en el párrafo tercero de ese mismo artículo:

El conjunto de servicios, infraestructura, redes, software, aplicaciones informáticas y dispositivos que tienen como propósito facilitar las tareas y funciones en los centros de trabajo, así como las que se necesitan para la gestión y transformación de la información, en particular los componentes tecnológicos que permiten crear, modificar, almacenar, proteger y recuperar esa información (DOF, 2021: 325).

Como se desprende de la definición anterior, el teletrabajo depende de los avances tecnológicos para su existencia en la relación laboral, y al ser una modalidad de reciente incorporación a la Ley Federal del Trabajo, poco se conoce respecto a los derechos con los que cuentan los trabajadores que laboran bajo esta modalidad. Sin embargo, un logro sobresaliente de la legislación mexicana en materia laboral fue la inserción del artículo 330-E, compuesto por ocho fracciones en las que se puntualizan los derechos a favor de los trabajadores bajo la modalidad de teletrabajo y que de alguna manera representan las obligaciones que contraen los patrones frente a sus teletrabajadores, mismas que la Secretaria de Trabajo y Previsión Social (STPS) resume y presenta en su página de internet mediante la imagen 1. Cabe destacar que la STPS 
agrega un noveno derecho, que no se encuentra en el artículo en comento, sin embargo, se encuentra inserto en el texto del artículo 330-H de la misma ley, respecto a la equidad de género en el teletrabajo.

\section{Imagen 1. Derechos de las personas trabajadoras en el Teletrabajo}

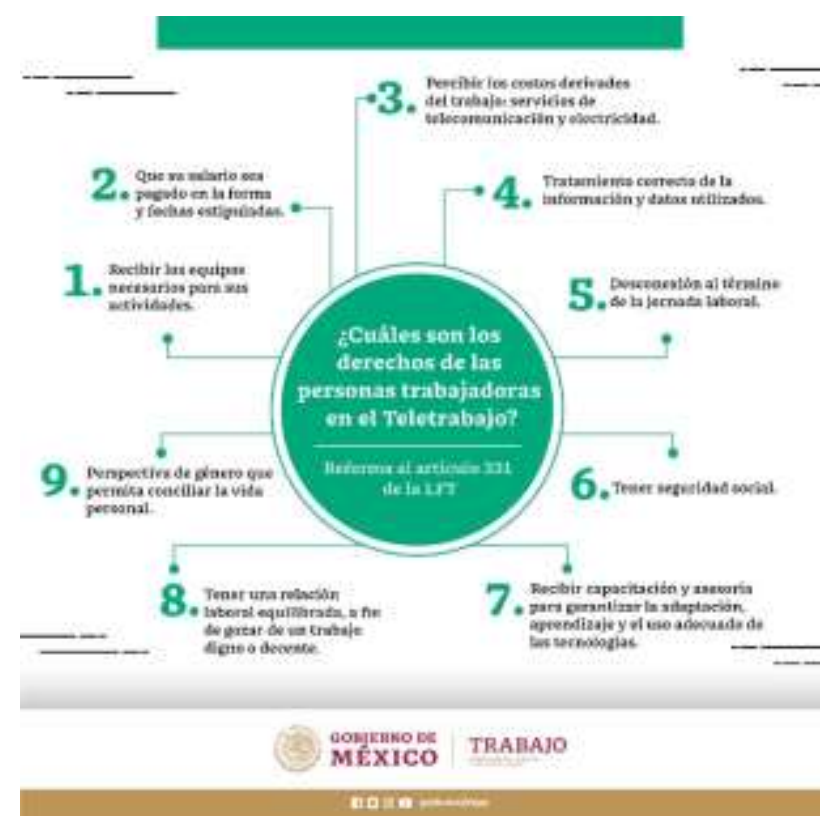

Fuente : Secretaria del Trabajo y Previsión Social

En cuanto los derechos plasmados en la imagen anterior hay mucho que comentar al respecto, sin embargo se retomará lo más relevante.

1. Recibir los equipos necesarios para sus actividades. El artículo 330-E fracción I de la Ley Federal del Trabajo establece la obligación de los patrones de proporcionar las herramientas y equipo necesario para que el trabajador pueda realizar su trabajo, ahora bien, dentro de esta primera fracción, resulta interesante la utilización de los términos: proporcionar, instalar y encargarse, dando pie a una serie de acciones que el patrón debe desarrollar frente a su trabajador.

Respecto al primer término, la fracción marca que el patrón deberá proporcionar entre otras cosas el equipo de cómputo, sillas ergonómicas e impresoras, sin embargo, esto crea para el patrón una carga económica que en muchos casos es difícil de solventar, sobre todo cuando el número de trabajadores bajo la modalidad de Teletrabajo aumenta de un momento a otro, como ocurrió en 2020 por motivo de la pandemia de Covid-19. Por lo que los trabajadores, a pesar de contar con este derecho a su favor, han tenido que hacer uso de su propio equipo de cómputo así como de adaptar un área de trabajo dentro de su domicilio.
Respecto a la obligación de instalar y encargarse del mantenimiento de los equipos existe un problema respecto a su determinación, ya que al ser una actividad fuera de los establecimientos del patrón, resulta difícil determinar si la falla del equipo fue producto del desgate por el uso normal o fue provocado por el uso inadecuado, ya sea por parte del trabajador o un tercero, sobre todo cuando dentro del domicilio del trabajador habitan los integrantes de su familia, los cuales son personas ajenas a la empresa y que al no haber una supervisión directa por parte del patrón pueden hacer uso del equipo para fines particulares.

Esa misma incertidumbre se presenta respecto al uso de los insumos como el papel, tinta de impresora, entre otros, dejando en desventaja al patrón al generarle un gasto extra por lo que a pesar de que la ley lo marca como una obligación del patrón, en la practica la realidad es otra.

2. Que su salario sea pagado en la forma y fecha estipuladas. El hecho de que el trabajador no se encuentre de manera física en el establecimiento del patrón no le resta derechos, a diferencia de aquellos trabajadores que si lo hacen, por lo que se deberá respetar lo estipulado en el contrato individual o colectivo, según sea el caso, y el patrón deberá respetar lo pactado respecto al medio de pago así como cubrir el salario en la fecha establecida, recordando que de acuerdo a la ley, el no hacerlo de esta manera representa una causa de recisión de la relación laboral sin responsabilidad para el trabajador en términos del artículo 51 fracción V de la Ley Federal del Trabajo.

3. Percibir los costos derivados del trabajo o servicio de telecomunicación y electricidad. La fracción III del artículo 330-E de la Ley Federal del Trabajo es ambigua respecto al alcance de este derecho al mencionar que el patrón deberá asumir los gastos de telecomunicación y electricidad, ya que el texto legal utiliza el término "proporcional" al referirse al monto que deberá cubrir por concepto de este último, lo que deja en duda hasta qué punto el pago del servicio de telefonía, servicio de internet así como de electricidad deberán correr por cuenta del patrón.

Tomando en cuenta que dichos servicios también son utilizados tanto por el trabajador como por su familia, esto pudiera traducirse en una explotación económica en contra del patrón.

Por otro lado, al no haber una norma que establezca los mecanismos para medir dicha proporcionalidad, el patrón ha dejado esa carga económica por cuenta del trabajador, sobre todo en aquellos trabajos que por la urgencia por motivo de la pandemia de coronavirus SARS-Cov2 tuvieron que emigrar al Teletrabajo sin 
realizar los ajustes necesarios en los contratos laborales respecto al pago de los servicios en comento.

4. Tratamiento correcto de la información y datos utilizados. En términos de la fracción $\mathrm{V}$ del artículo en comento, una de las obligaciones del patrón es implementar los mecanismos necesarios para garantizar la seguridad respecto a la información y datos utilizados por las personas que laboran bajo la modalidad de teletrabajo, lo que se puede entender en dos vías:

a) Respecto al cuidado de la información personal del trabajador, ya que como se mencionó en el punto número uno, es común que el equipo de cómputo que se utiliza para el teletrabajo sea propiedad del empleado lo que lo hace propenso al robo de información personal almacenada dentro del equipo. En este sentido, es igualmente importante referirse a la limitación respecto al uso de cámaras y micrófonos para la supervisión del teletrabajo, salvo casos extraordinarios, esto con la finalidad de preservar la intimidad del hogar del trabajador, todo esto atendiendo a lo establecido en el artículo 330-I de la Ley Federal del Trabajo.

b) En cuanto al resguardo de la información confidencial del patrón o de la empresa a la que por motivos de trabajo tiene acceso el empleado, esto bajo el supuesto de que al no encontrarse en el establecimiento del patrón disminuye la seguridad cibernética a la que tendría acceso si laborará en él.

En cualquiera de los dos casos, sea la información personal del trabajador o del resguardo de la información confidencial del patrón, este último deberá garantizar que los datos estarán a salvo para que el trabajador pueda laborar con esa certidumbre.

5. Desconexión al término de la jornada laboral. Sin duda alguna, este derecho a favor de los trabajadores bajo la modalidad de Teletrabajo es uno de los más valorados, ya que, al laborar desde su domicilio, hace difícil marcar el límite respecto a su jornada laboral. En palabras de Juan René Segura (2021), se corre el peligro de prolongar la jornada laboral a mucho más que solamente ocho horas.

En este supuesto, las empresas tienden a querer controlar a sus trabajadores por distintas vías como los correos electrónicos, llamadas telefónicas, mensajes vía WhatsApp, videoconferencias.

Lo anterior, generalmente se efectúa fuera del horario de labores, por lo que este derecho le confiere al trabajador la posibilidad de apagar sus dispositivos electrónicos 0 de telecomunicación, o en su defecto, de no contestar a cualquiera de estos intentos de comunicación que el patrón realice fuera de los horarios convenidos sin que haya algún tipo de represalia en contra del trabajador. Todo esto con la finalidad de garantizarle el respeto de su tiempo personal y familiar.
Por tanto, como menciona Pérez Amorós (2020), la desconexión se activa fuera de la jornada laboral, ya que de no hacerlo resultaría una prolongación indebida de su jornada laboral.

6. Tener Seguridad Social. Uno de los motivos de la incorporación del Capítulo XII Bis, en materia del Teletrabajo, fue el de garantizar que los trabajadores bajo esta modalidad gozaran de los mismos beneficios a los que tiene derecho un trabajador que desempeña sus labores en el establecimiento del patrón, incluyendo el ser dado de alta bajo el Régimen Obligatorio de la Seguridad Social.

7. Recibir capacitación y asesoría para garantizar la adaptación, aprendizaje y el uso adecuado de las tecnologías. Una de las prestaciones mínimas de ley a las que todo trabajador tiene derecho es a la capacitación y adiestramiento, por lo que no es de extrañar que se retome esta obligación por parte del patrón hacia sus subordinados sobre todo tratándose de un tema que puede resultar nuevo para el trabajador que opera mediante el teletrabajo.

Durante el año 2020 un gran número de trabajadores se vieron en la necesidad de trasladarse a sus hogares para operar desde ahí y muchos de ellos lo hicieron sin recibir la capacitación adecuada.

Hasta cierto punto, esa ausencia de asesoramiento fue comprensible por la urgencia del momento, ya que las empresas probablemente no lo hubiesen hecho bajo una situación normal, por lo que los trabajadores se enfrentaron a un reto de aprendizaje en el que tuvieron que volverse autodidactas respecto al uso de las tecnologías de información y comunicación para poder sacar adelante el trabajo encomendado. Sin embargo, pasada la urgencia que en ese momento operaba, y con el reconocimiento del derecho a la capacitación, los patrones deberán implementar las estrategias y mecanismos para proporcionarla a sus trabajadores que laboran a distancia.

Ese deber por parte de los patrones resulta del resumen ejecutivo de la OIT (2021), en el que afirma que los trabajadores que prestan sus servicios fuera de los establecimientos del patrón tienen un menor índice de acceso a la información, por lo que es menos probable que los teletrabajadores aprovechen las oportunidades de formación, lo cual genera una desventaja para su crecimiento profesional y afecta en gran medida su perspectiva de carrera.

8. Tener una relación laboral equilibrada, a fin de gozar de un trabajo digno y decente. La dignidad en el trabajo puede observarse desde diferentes criterios, uno de ellos tiene que ver con la remuneración. De acuerdo a la OIT (2021), los salarios en México para los trabajadores a domicilio son en promedio cincuenta por ciento inferiores 
en comparación con los que perciben los trabajadores que laboran de manera presencial en las empresas, por lo que se debe garantizar una igualdad en ese sentido.

Otro criterio tiene que ver con las jornadas de trabajo, ya que sus horas reales de trabajo son inciertas, generando estrés al trabajador, debido a que la línea entre el horario de trabajo y tiempo personal o familiar no está claramente delimitada.

9. Perspectiva de género que permita conciliar la vida personal. De acuerdo con datos de la OIT (2021), en 2019 se estimaba un aproximado de 260 millones de personas laborando desde su domicilio, de los cuales 147 millones eran mujeres, habiendo $11.5 \%$ de propensión al trabajo a domicilio por parte del género femenino, esto debido a que mediante la modalidad de Teletrabajo cuentan con la flexibilidad de horarios que le permiten desarrollar sus demás responsabilidades familiares y domésticas. Es por ello que el legislador prevé la perspectiva de género en el artículo $330-\mathrm{H}$, con el fin de garantizar un equilibrio entre la jornada laboral y la vida personal.

\section{Las obligaciones en el Teletrabajo}

De la adición del capítulo XII Bis, no solo se derivan facultades sino también obligaciones a las que los trabajadores deben sujetarse para que la relación laboral subsista, las cuales se encuentran establecidas en el artículo 330-F de la Ley Federal del Trabajo y que al igual que con los derechos, la Secretaria de Trabajo y Previsión Social se dio a la tarea de resumirlas en la imagen que se presenta a continuación.

Imagen 2. Obligaciones de las personas trabajadoras en el Teletrabajo

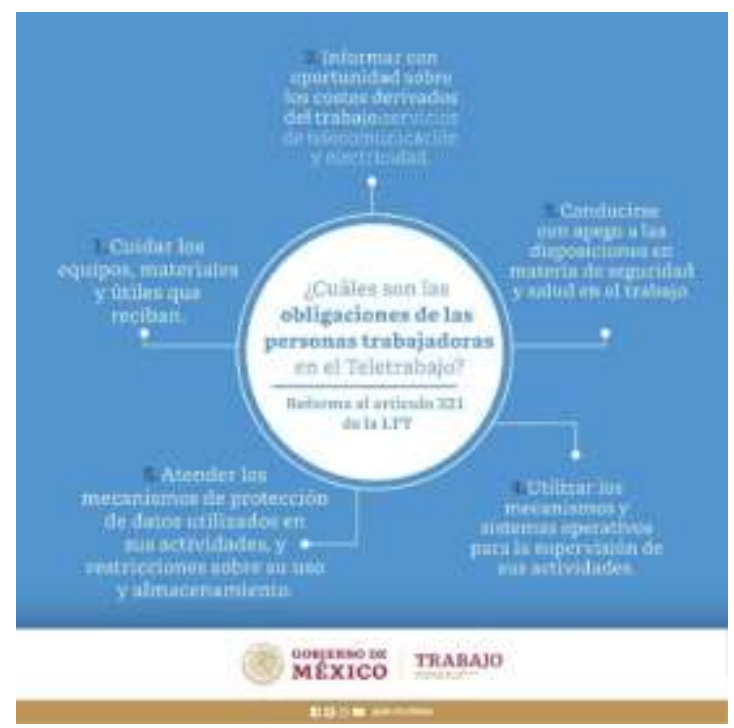

Fuente : Secretaria del Trabajo y Previsión Social
Como se puede observar en la imagen anterior, existen cinco obligaciones principales que los trabajadores deberán respetar cuando laboren bajo el sistema de Teletrabajo. Cabe mencionar que no son las únicas, ya que igualmente deberán acatar las obligaciones establecidas para los trabajadores en general. Sin embargo, estas cinco adquieren relevancia para el presente documento, porque fueron establecidas específicamente para ser observadas por los teletrabajadores, las cuales son:

1. Cuidar los equipos, materiales y útiles que reciban. Llama la atención que el texto legal utilice la expresión "tener el mayor cuidado" al referirse en el artículo 330-F en su fracción I, a la guarda y conservación de los equipos, pues de ese modo se da cierta consideración al trabajador, ya que al encontrarse el equipo dentro de su hogar, se entiende que corre mayor peligro de sufrir algún accidente que pueda dañarlo o simplemente el ser objeto del desgaste por su uso normal.

Por otro lado, aunque la ley no lo expresa de forma específica en este apartado, en términos del artículo 134 fracción VI de la Ley Federal del Trabajo, también se establece como una obligación de todos los trabajadores, sin importar bajo que modalidad laboren, el restituir al patrón los materiales no usados, lo que aplicado específicamente al sistema del Teletrabajo, en caso de la disolución de la relación laboral, el teletrabajador deberá entregar el equipo de cómputo, la silla ergonómica, la impresora y demás herramientas que le hayan sido proporcionadas por su empleador.

2. Informar con oportunidad sobre los costos derivados del trabajo o servicios de telecomunicación y electricidad. La ley no marca el plazo en que el trabajador bajo la modalidad de Teletrabajo deberá entregar dicha información ni tampoco la forma en que deberá presentarla, por lo que la obligación de informar con oportunidad puede referirse a enterar a su patrón desde antes $\mathrm{o}$ al inicio de las actividades bajo la modalidad de Teletrabajo.

Si la información es proporcionada al inicio, deberá ser plasmado en el contrato laboral en donde tanto patrón y trabajador podrán acordar el monto correspondiente para ese efecto, o bien, inmediatamente después de que el trabajador reciba el estado de cuenta a pagar por concepto de luz eléctrica, telefonía o Internet con la finalidad de que el patrón realice el pago correspondiente o en su defecto, reembolse al trabajador el gasto generado.

A este respecto, mientras no exista una disposición que establezca con claridad dichos plazos, será mediante acuerdo de las partes involucradas en que se fije el tiempo y la forma en que el trabajador deberá enterar los 
costos a su patrón, teniendo la obligación el primero de sujetarse a los lineamientos establecidos.

3. Conducirse con apego a las disposiciones en materia de seguridad y salud en el trabajo. Al ser una figura de reciente incorporación a la legislación mexicana, existen muchas dudas y lagunas legales al respecto. Sin embargo, de acuerdo al segundo artículo Transitorio del Decreto publicado por el Diario Oficial de la Federación, en donde se reforma el artículo 311 y se adiciona el capítulo XII Bis (DOF, 2021) se establece un plazo de dieciocho meses a partir de su entrada en vigor para que el Poder Ejecutivo Federal emita una Norma Oficial Mexicana, con la finalidad de regir las obligaciones en materia de Seguridad y Salud para los trabajadores que se encuentren en el sistema de Teletrabajo, por lo que una vez emitida la Norma Oficial Mexicana, el trabajador tendrá la obligación de sujetarse a sus lineamientos.

Mientras eso sucede, el patrón deberá establecer lineamientos en materia de Seguridad y Salud en el Trabajo para sus trabajadores en modalidad de Teletrabajo atendiendo a la fracción III del artículo 330-F.

4. Utilizar los mecanismos operativos para la supervisión de sus actividades. Como se explicó respecto al derecho a favor del trabajador sobre el tratamiento correcto de la información y datos utilizados, es obligación del patrón establecer los mecanismos necesarios para garantizar esa seguridad, respetando la limitación en cuanto al uso de cámaras y micrófonos dentro del domicilio del teletrabajador para no vulnerar su privacidad.

Sin embargo, esa limitación no excluye al trabajador de ser vigilado y supervisado durante su jornada laboral, por lo que deberá utilizar el equipo y sistemas operativos que el patrón le indique para dicho objetivo, siempre y cuando se cumpla con los requerimientos establecidos por la ley, atendiendo el marco jurídico aplicable en materia de protección de datos personales.

5. Atender los mecanismos de protección de datos utilizados en sus actividades, y restricciones sobre su uso y almacenamiento. De la misma manera que se comentó en el numeral anterior, el trabajador tendrá la obligación de utilizar y acatar los mecanismos que el patrón le indique con la finalidad de proteger los datos. Ahora bien, respecto a las restricciones sobre su uso y almacenamiento, se puede deducir que se aplica cuando el equipo es proporcionado por el patrón, por ejemplo, tratándose de discos duros, computadoras, entre otros, ya que su rendimiento se puede ver afectado si el trabajador lo utiliza para fines ajenos a la empresa, reservándose entonces el uso exclusivamente para el teletrabajo.

\section{Conclusiones}

El teletrabajo fue ignorado durante mucho tiempo por la legislación mexicana, ya que gira entorno de los desarrollos tecnológicos y en ese sentido México se encuentra rezagado en comparación de las demás naciones que cuentan con un mayor desarrollo económico. Sin embargo, por causa de la pandemia de Covid-19 no hubo más remedio que trabajar a marchas forzadas para su reconocimiento en la Ley Federal del Trabajo, por tanto, la pandemia no hizo más que acelerar lo que en definitiva debía suceder en algún momento.

Con la reforma al artículo 311 y la incorporación del Capítulo XII Bis en materia de Teletrabajo se está subsanando una laguna legal respecto a esta forma especial de trabajo, quedando pendiente la publicación de la Norma Oficial Mexicana que regirá en materia de Seguridad y salud en materia de Teletrabajo.

Ante la migración de miles de trabajadores a la modalidad de Teletrabajo, por causa del confinamiento por Covid-19, era necesario que se regulara en la legislación mexicana para evitar la violación de los derechos de los trabajadores y de alguna manera darles certeza jurídica, no solo a ellos sino también a los patrones, quienes no sabían a ciencia cierta hasta donde llegaban sus responsabilidades, sobre todo porque la implementación del sistema de Teletrabajo en diversas empresas no solo aplicará durante el tiempo que dure la pandemia sino que en algunos casos será permanente 0 de forma hibrida.

\section{Referencias}

AMET (2002). "Acuerdo Marco Europeo sobre Teletrabajo". Confederación Europea de Sindicatos (En línea). Disponible en: https://www.ccoo-

servicios.es/archivos/altamira/20110727_acuerdo_marco_europeo tele trabajo.pdf [17 de julio de 2021]

Dávalos, José (2008). Derecho individual del trabajo. México: Porrúa.

DOF (2021) “Diario Oficial de la Federación”. SEGOB (En línea). Disponible http://dof.gob.mx/nota_detalle.php?codigo $=5609683 \&$ fecha $=11 / 01 / 20$ 21 [17 de julio de 2021]

DOF (2021) "Ley Federal del Trabajo". Cámara de Diputados (En línea). Disponible http://www.diputados.gob.mx/LeyesBiblio/pdf/125_230421.pdf [17 de julio de 2021]

INEGI (2020). "Encuesta telefónica sobre Covid-19 y mercado laboral (ECOVID-ML) Resultados de abril 2020”. INEGI [En línea]. México. Disponible

en: https://www.inegi.org.mx/contenidos/investigacion/ecovidml/2020/ doc/ecovid_ml_presentacion.pdf [20 de julio de 2021]

Machicado, Jorge (2010) Historia del derecho del trabajo. Bolivia: Ediciones New Life 
Margadant, Guillermo Floris (2007) Panorama de la Historia universal del Derecho. México: Porrúa

OIT (1996) "Convenio sobre trabajo a domicilio, 1996". International Labour Organization (En línea). Disponible en: https://www.ilo.org/dyn/normlex/es/f?p=NORMLEXPUB:12100:0::N O::P12100 INSTRUMENT ID:312322\#A1 [17 de julio de 2021]

OIT (2020). "El teletrabajo durante la pandemia de COVID-19 y después de ella, Guía práctica" International Labour Organization [En línea]. Ginebra: OIT. Disponible en: https://www.ilo.org/wcmsp5/groups/public/---ed protect/---protrav/--travail/documents/publication/wcms 758007.pdf [20 de julio de 2021]

OIT (2021). "El trabajo a domicilio, de la invisibilidad al trabajo decente, Resumen ejecutivo". International Labour Organization [En línea]. México. Ginebra. Disponible en: https://www.ilo.org/wcmsp5/groups/public/---ed_protect/---protrav/--travail/documents/publication/wcms 765898.pdf [17 de julio de 2021]

OIT (2021). "Teletrabajo". ILO Thesaurus (En línea). Disponible en: https://metadata.ilo.org/thesaurus/-1359993413.html [17 de julio de 2021]

Organización panamericana de la salud (2020). "La OMS caracteriza a COVID -19 como pandemia” Organización Panamericana de la Salud [En línea]. Ginebra: OPS. Disponible en: https://www.paho.org/es/noticias/11-3-2020-oms-caracteriza-covid-19como-pandemia [21 de julio de 2021]

Pérez Amorós, Francisco (2020). "Derecho de los trabajadores a la desconexión digital: mail on holiday" en Revista IUS [En línea]. Vol. 14, núm. 45, pp. 257-275. Puebla: Instituto de Ciencias Jurídicas de Puebla, Departamento de Investigaciones. Disponible en: https://www.redalyc.org/articulo.oa?id=293264642013 [5 de julio de 2021]

Segura, Juan René (2021) "El teletrabajo y su regulación jurídica después del Covid 19" en Revista Iberoamericana del Derecho de trabajo y de la seguridad social [En línea].Vol. 3, Núm. 5, pp. 46-60.México: Asociación Iberoamericana de Derecho del Trabajo y de la Seguridad social "Guillermo Cabanellas". Disponible en: http://aidtss.org/revistaiberoamericana/index.php/main/article/view/83/ $\underline{75}$ [5 de julio de 2021]

Weller, Jürgen (2020). "La pandemia del COVID-19 y su efecto en las tendencias de los mercados laborales" Documentos de Proyectos [En línea]. Santiago: Comisión Económica para América Latina y el Caribe (CEPAL) disponible en: https://repositorio.cepal.org/bitstream/handle/11362/45759/1/S200038 7_es.pdf [21 de julio de 2021]

\section{NOTAS}

\footnotetext{
i Alfonso Cravioto Mejorada (1883-1958) fue Diputado al Congreso Constituyente de Querétaro (1916-1917) y se le reconoce por su participación en la discusión de los artículos $3^{\circ}, 5^{\circ}, 22,32$ y 84 .

ii Eslovenia ratificó el Acuerdo 177 sobre el trabajo a Domicilio el 14 de abril de 2021 y entrará en vigor el 14 de abril de 2022.

iii Tesauro de la OIT es una compilación de más de 4000 términos relacionados con el mundo del trabajo en inglés, francés y español.
} 